\title{
Vaso con decoración cardial de Cova Eirós (Triacastela, Lugo)*
}

\author{
A cardial decorated vessel from Cova Eirós (Triacastela, Lugo)
}

\section{Ramón Fábregas Valcarce, António Faustino Carvalho ${ }^{\mathrm{b}}$, Arturo de Lombera-Hermidaa, c, d, Miriam Cubas, , , Alexandre Lucquine, Oliver Edward Craig ${ }^{e}$ y Xosé Pedro Rodríguez- Álvarez ${ }^{\mathrm{c}, \mathrm{d}}$}

\section{RESUMEN}

El hallazgo de un vaso cerámico parcialmente conservado en el curso de las excavaciones llevadas a cabo en Cova Eirós permite aportar nuevos datos sobre la cultura material del Neolítico regional. El recipiente, tanto por su forma de botella como por su decoración (impresión de concha), recuerda claramente a la cerámica cardial, tan característica del registro arqueológico entre los primeros grupos neolíticos del sur de la península ibérica. Se abordan las circunstancias del hallazgo y los paralelos más cercanos, que se encuentran entre las colecciones cerámicas del sur de Portugal. A modo de conclusión, sugerimos que la pieza analizada se remonta probablemente al final del VI milenio a. C.

\begin{abstract}
The discovery of a partially preserved vessel in the course of the excavations carried out in Cova Eirós brings forth new data on the material culture of the regional Neolithic. The pot, both in its bottle-like shape and decoration (shell impressed), recalls strongly the cardial ware, so characteristic of the archaeological record in the Early Neolithic groups of South Iberia. We discuss the circumstances of the finding and the closest parallels to be found among the pottery collections from South Portugal. As a result, we sug-
\end{abstract}

gest that the vessel found at Cova Eirós would date back to the end of the 6th Millennium BC.

Palabras clave: Noroeste de la península ibérica; Neolítico; Alfarería cardial; Prehistoria Reciente.

Key words: Iberian Northwest; Neolithic; Cardial Ware; Late Prehistory.

\section{EL NEOLÍTICO GALLEGO: STATE OF THE ART}

La investigación sobre el tránsito a una economía productora y las primeras comunidades agropastoriles galaicas sólo tardíamente comenzó a abordarse: el hecho de la -aparente- inexistencia en el noroeste ibérico de los elementos estructurales (poblados u ocupaciones cavernarias) o artefactuales canónicos de esas iniciales etapas en el sur y levante peninsulares (i.e., cerámicas impresas), conllevará que el Neolítico gallego pase a ser "el periodo que nunca existió" en la tradición historiográfica regional (Fábregas y Suárez 1999: 541). Una particular tradición funeraria (megalitismo), ciertamente nacida en el Neolítico -aunque

* Las intervenciones en Cova Eirós fueron financiadas por el Ministerio de Economía (HAR2010-21786) y la Consellería de Cultura, Educación e Ordenación Universitaria de la Xunta de Galicia.

a Grupo de Estudos para a Prehistoria do Noroeste. Arqueoloxía, Antigüidade e Territorio (GEPN-AAT). Dpto. de Historia. Facultade de Xeografía e Historia. Universidade de Santiago de Compostela. Praza da Universidade 1. 15782 Santiago de Compostela. Correo e.: ramon.fabregas@usc.es https://orcid.org/0000-0002-7940-6884; AL-H https://orcid.org/0000-0001-9199-6242.

b Universidade do Algarve, Faculdade de Ciências Humanas e Sociais, Dpto. de Artes e Humanidades. Campus de Gambelas. 8000-117 Faro. Portugal. https://orcid.org/0000-0002-0912-2325

c Institut Català de Paleoecologia Humana i Evolució Social (IPHES). C/ Marcel·lí Domingo s/n. Campus Sescelades. Universitat Rovira i Virgili (Edifici W3). 43007 Tarragona. https://orcid.org/0000-0002-1852-2283

d Área de Prehistoria, Universitat Rovira i Virgili (URV). Avinguda de Catalunya 35. 43002 Tarragona.

e BioArCh-Department of Archaeology. University of York. Environment Building. Wentworth Way. Heslington. York. YO10 5DD. United Kingdom. MC https://orcid.org/0000-0002-2386-8473; AL https://orcid.org/0000-0003-4892-6323; OEC https://orcid.org/0000-0002-4296-8402

f Sociedad de Ciencias Aranzadi. C/ Alto de Zorroaga 11. E-20014. Donostia-San Sebastián.

Recibido 30-I-2018; aceptado 21-V-2018. y distribución "Creative Commons Reconocimiento 4.0 Internacional” (CC BY 4.0). 
no limitada a este periodo-, sustituye al periodo cronocultural en su conjunto. Esta peculiar sustitución de la parte por el todo responde sin duda a una investigación centrada exclusivamente en los aspectos más monumentales del registro, a causa de las limitaciones de este último pero también debido a carencias de orden metodológico, vinculadas a la tardía institucionalización de la arqueología en Galicia.

La anomalía histórica que representaba la inexistencia de un periodo neolítico en Galicia comenzó a ponerse de manifiesto a inicios de los 1980 por parte de dos investigadores locales (Vázquez 1980; Suárez 1983). Significativamente, esa primera definición de un Neolítico regional -previo al fenómeno megalíticose fundaba en el descubrimiento en dos yacimientos en la costa suroeste gallega de unos restos cerámicos decorados con una técnica (impresión de concha), que evocaba los rasgos formales de los muy conocidos conjuntos cardiales del sur y este de la península ibérica. Desgraciadamente, las propias cerámicas y el contexto de esos yacimientos carecían de la necesaria definición en términos cronológicos, por lo que la propuesta de dichos autores se mantuvo en un cierto limbo por parte de la comunidad científica.

Hay que aguardar a la década de 1990 para que comencemos a disponer de datos más sólidos sobre el primer Neolítico, en gran medida provenientes del norte de Portugal, donde algunos yacimientos como Buraco da Pala, así como hallazgos efectuados bajo construcciones tumulares, permiten diseñar un horizonte caracterizado por una alfarería decorada mediante impresión arrastrada ("boquique") o acanalados, cuya estilística decorativa y el C14 emplazan en la primera mitad del V milenio cal AC (p. ej., Sanches 1997). Por otra parte, algunos análisis paleobotánicos (polen y carpología) apoyan un inicio, siquiera tenue, de las actividades agrícolas en esos parámetros temporales (Fábregas et al. 1997: 469), previos por lo tanto a las primeras construcciones tumulares.

Transcurrida la década del 2010 seguimos teniendo dificultades para caracterizar en detalle los yacimientos del Neolítico Antiguo galaico, fundamentalmente porque las escasas dataciones radiométricas disponibles provienen de estructuras negativas (hornos, fosas o diversas excavaciones de diseño lineal) que en general no están inequívocamente asociadas a materiales arqueológicos diagnósticos o ecofactos; un buen ejemplo de este problema acontece en el sitio de Monte dos Remedios (Moaña, Pontevedra) (Fábregas et al. 2007). La cultura material está representada principalmente por cerámicas decoradas, entre las que sin embargo la impresión mediante matriz de concha es muy escasa -un solo vaso recuperado en un nivel intacto de la cámara de Parxubeira 3 (Mazaricos, A Coruña) (Rodríguez Casal 1989,
1990: 110)- frente a otros tipos de impresión (punzón, "boquique") o a incisiones y acanalados. Los yacimientos conocidos se localizan preferentemente en la mitad sur del territorio, emplazados en una variedad de posiciones topográficas, desde las penillanuras de las sierras litorales hasta la planicie costera, compareciendo al aire libre pero ocasionalmente bajo abrigos rocosos.

En el presente estado de nuestros conocimientos, la transición a una economía productora habría acontecido en una cronología más o menos sincrónica con la apuntada para el norte de Portugal y la Región Cantábrica, probablemente en la primera mitad del V milenio cal AC. Por otra parte, no es descartable que, como se ha apuntado recientemente para esa última área (Cubas et al. 2016), la aparición de los primeros animales domésticos (que no una ganadería económicamente relevante) preceda en algunos siglos a la agricultura. Esta dinámica particular podría afectar a las regiones más interiores y septentrionales de Galicia, cuyos rasgos biogeográficos las alejan en mayor medida de las zonas allende el Duero. Es probable que los primeros cultígenos y algunos trazos de la cultura material, como la cerámica o ciertas variedades de sílex, provengan precisamente de los territorios situados más allá del Miño. No obstante, otros elementos apuntan la posibilidad de que esa conexión meridional estuviese complementada con unos contactos relativamente tempranos con Bretaña, si prestamos atención a la presencia de algún vaso de tipo Castellic (Cassen et al. 2012: 979) o a las fechas igualmente antiguas que se obtuvieron en el occidente francés para adornos en variscita, una materia prima procedente en ocasiones de las fuentes zamoranas de dicho mineral (Querré et al. 2015), cuya exportación hacia tierras francesas tendría que haber seguido los valles fluviales que desembocan en el Atlántico. La aparición de hachas en jadeíta de probable origen alpino en el NO peninsular puede ponerse en relación con dicha red de circulación, si bien su contexto arqueológico y cronológico es más difuso (Fábregas et al. 2012a, 2017).

\section{CIRCUNSTANCIAS DEL HALLAZGO DEL VASO IMPRESO DE COVA EIRÓS}

Cova Eirós es una cavidad localizada a una altitud de $785 \mathrm{~m}$ s. n. m., sobre una ladera del Macizo de monte Penedo, orientada al nornoroeste y dominando un pequeño valle en el lugar de Cancelo (Triacastela, Lugo) (Fig. 1). Este yacimiento presenta una ubicación privilegiada desde el punto de vista de las comunicaciones, ya que se encuentra cerca de una divisoria que da paso a valles que se abren hacia el Cantábrico si-

Trab. Prehist., 76, N. ${ }^{\circ}$ 1, enero-junio 2019, pp. 147-160, ISSN: 0082-5638

https://doi.org/10.3989/tp.2019.12231 


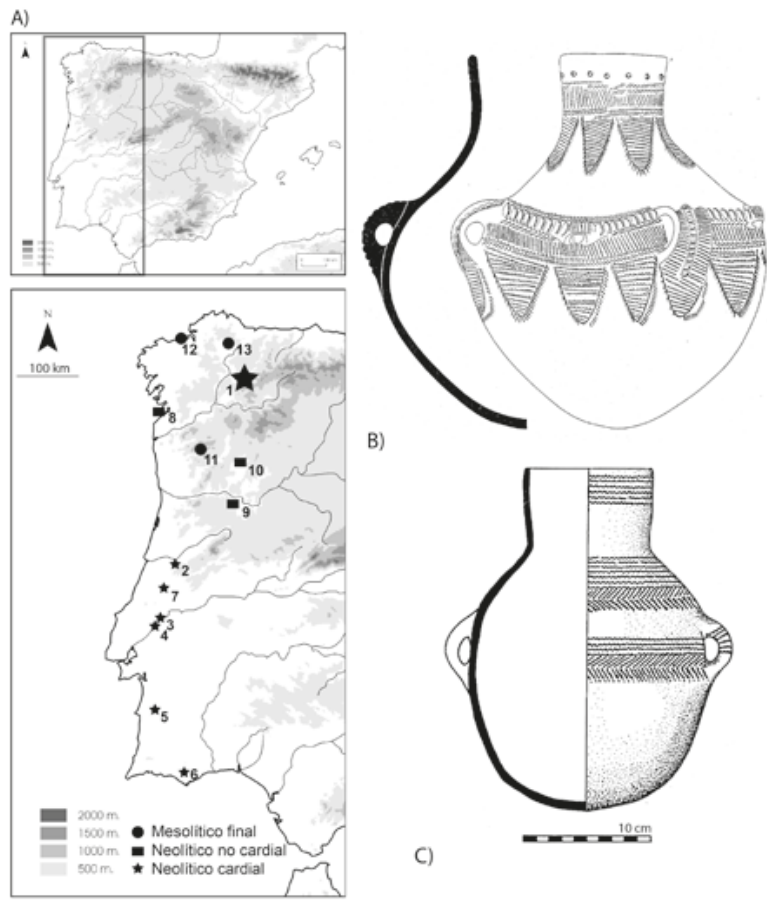

Fig. 1. Localización en la zona occidental de la península ibérica de Cova Eirós (Triacastela, Lugo) y los principales yacimientos mencionados en el texto: 1. Cova Eirós; 2. Casével; 3. Santarém; 4. Cartaxo; 5. Monte da Vinha; 6. Retorta; 7. Galería da Cisterna; 8. Abrigo 2 de A Cunchosa; 9. Prazo; 10. Buraco da Pala; 11. Abrigo 1 de Vale Cerdeira; 12. O Reiro; 13. As Pontes. B. Cerámica cardial de Casével (Pessoa 1983: Fig. 3). C. Vaso de Santarém (Guilaine e Ferreira: 1970, Fig. 3).

guiendo el curso del río Navia y hacia la cuenca del Miño, respectivamente. Por otra parte, en sus inmediaciones discurre una de las rutas naturales, históricamente importante, que permite atravesar la cadena montañosa que separa Galicia de Castilla (Camino de Santiago). Por lo tanto, pese a su posición geográfica en apariencia marginal, Cova Eirós se dispone en una encrucijada de comunicaciones que da acceso a una variedad de biotopos y facilitan la aproximación al Cantábrico o al Baixo Miño, además de cruzar hacia la Meseta española.

Si bien la mayor cantidad de hallazgos arqueológicos en este lugar corresponde al periodo pleistoceno y, mucho más tarde, a actividades de época altomedieval (Rodríguez-Álvarez et al. 2011; Teira et al. 2012; Lombera et al. 2014; Rey-Rodríguez et al. 2016), existen tanto en la entrada como en la gran sala interior de la cueva restos materiales pertenecientes a la Prehistoria Reciente, comenzando por un enterramiento dentro de la cavidad datado a mediados del IV milenio cal AC y algunos fragmentos cerámicos recuperados en el sector de la entrada que se podrían encuadrar en momentos posteriores, calcolíticos o incluso del Bronce Final (Tab. 1) (Fábregas et al. 2012b: 24; Lombera et al. 2014). Sin embargo, carecemos por ahora de materiales o estructuras que pudieran asociarse en términos cronoculturales con el recipiente cerámico que vamos a analizar a continuación.

Los fragmentos que componen la vasija aparecieron incorporados a la sección norte de la excavación, relacionados con una fosa (UA8) excavada sobre los niveles superficiales y pleistocenos de la secuencia, que alcanzaba una profundidad de unos $60 \mathrm{~cm}$ y presentaba una sección cóncava y abierta (Fig. 2). Asociados a esta fosa se recuperaron varios restos faunísticos, líticos y cerámicos (de cronología medieval) procedentes de la remoción de dichos niveles $(n=51)$. Los tres fragmentos cardiales aparecieron justo en la base de la misma, insertados en la sección estratigráfica y muy próximos entre sí, estando dos de ellos en conexión con fracturas antiguas. Por desgracia, este sector de la excavación se encuentra bastante alterado por bioturbación (principalmente madrigueras) y la construcción de estructuras y fosas de época altomedieval, lo que impide aventurar cualquier interpretación funcional de la misma. Su posición, muy próxima al conducto de una de esas madrigueras, puede explicar la rotura del recipiente y la dispersión de sus restos, si bien es posible que gran parte del mismo se encuentre todavía en la sección no excavada. En este sentido, a este conjunto debemos sumarle un fragmento recuperado en los niveles superficiales de los cuadros adyacentes (E25, campaña 2008), que se corresponde con un arranque de asa (Fábregas et al. 2012b). Por las características morfológicas, de la pasta y la técnica decorativa, dicho fragmento puede ser sin duda adscrito al recipiente que nos ocupa (Fig. 3c).

\begin{tabular}{|l|l|l|l|l|l|}
\hline Muestra & Procedencia & Ref. Lab. & $\begin{array}{l}\text { Datación } \\
\text { radiocarbónica }\end{array}$ & $\begin{array}{l}\text { Fecha calibrada } \\
\mathbf{( 9 5 , 4 \% )}\end{array}$ & Ref. bibliográfica \\
\hline Hueso humano & Cata del Pasillo & Ua-38121 & $3151 \pm 31 \mathrm{BP}$ & $1500-1310 \mathrm{cal} \mathrm{BC}$ & Vidal et al. 2010 \\
\hline Falange humana & Cata interior Gran Sala & Beta-356716 & $4750 \pm 30 \mathrm{BP}$ & $3637-3382 \mathrm{cal} \mathrm{BC}$ & Inédita \\
\hline
\end{tabular}

Tab. 1. Dataciones radiocarbónicas obtenidas para los restos humanos recuperados en el interior de Cova Eirós. La calibración se ha hecho mediante el programa Oxcal 4.3 (Bronk Ramsey 2009) utilizando las curvas de calibración de Reimer et al. 2013. 


\section{EL VASO IMPRESO DE COVA EIRÓS}

\subsection{Descripción morfológica y estilística}

No es posible proceder a la reconstrucción integral de la morfología del vaso, pues los fragmentos recuperados, que permiten un remontaje, se ciñen a su tercio superior. Esta sección de la pieza supone, de todas formas, una proporción muy significativa de su perfil original, comprendiendo en particular la zona de la boca, circunstancia que nos permitirá efectuar varias observaciones (Fig. 3).

En términos morfológicos, el vaso de Cova Eirós presenta un cuello muy bajo (menos de $5 \mathrm{~cm}$ de altura) y estrecho (alrededor de $7 \mathrm{~cm}$ de diámetro a nivel de la boca), con borde recto y labio convexo. El cuerpo del recipiente alcanzaría un diámetro estimado de unos $20 \mathrm{~cm}$ y el grosor de las paredes (alrededor de los $0,5-0,7 \mathrm{~cm}$ ) sugiere que la altura máxima de la vasija no llega a los $50 \mathrm{~cm}$ aunque la

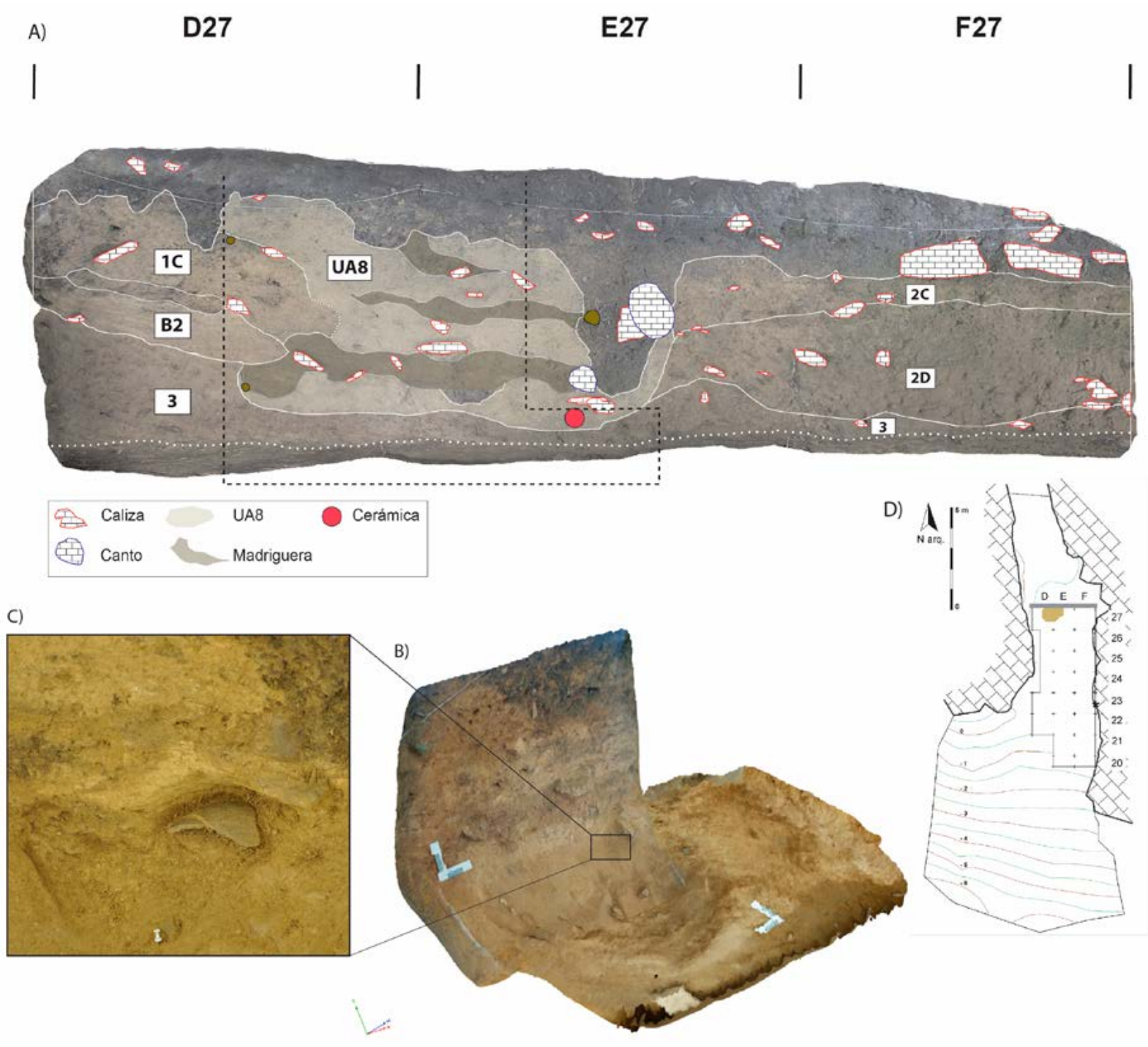

Fig. 2. Contexto estratigráfico de la cerámica cardial en Cova Eirós: A. Perfil estratigráfico norte de la excavación con la localización de los niveles, la UA8 y la cerámica cardial (en línea discontinua sector representado en la fotogrametría). B. Fotogrametría de la base de la UA8 y localización del punto donde se recuperó la cerámica. C. Detalle in situ de la cerámica. D. Localización con respecto a la superficie de excavación (fotogrametría A. Vázquez Martínez; en color en la versión electrónica). 


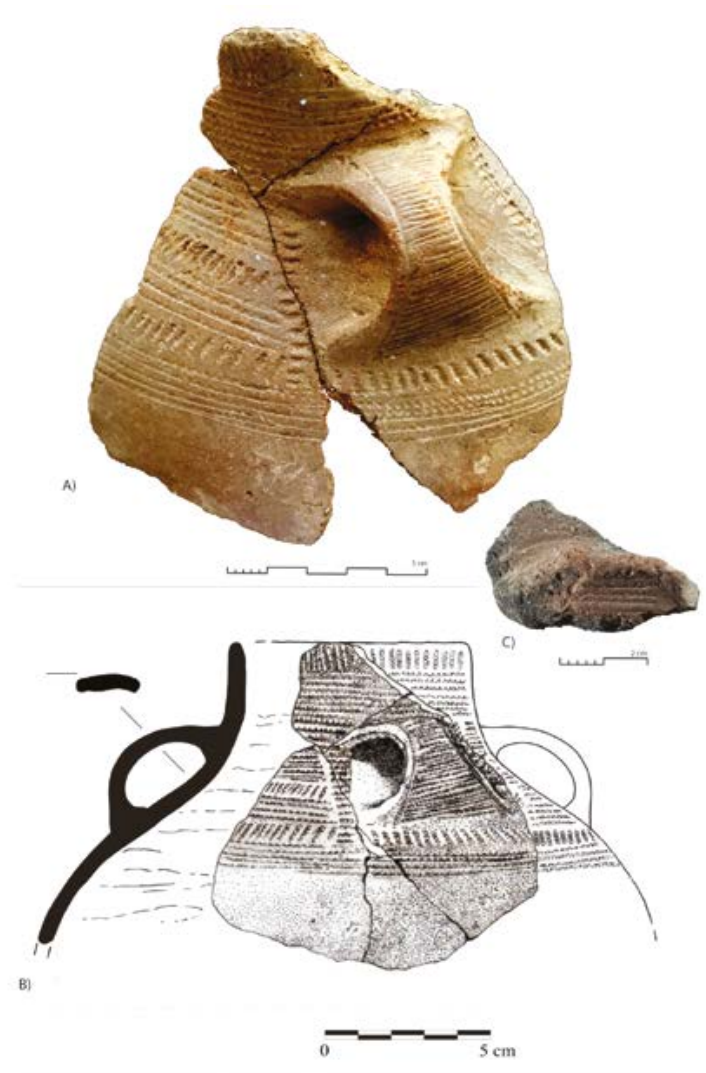

Fig. 3. Cerámica cardial de Cova Eirós: A-B. Fotografía y dibujo. C. Fragmento del arranque de asa recuperado en la campaña de 2008 (dibujo X. Constela; A y C en color en la edición electrónica).

morfología del tercio inferior de la pieza nos sea totalmente desconocida. En términos tipológicos, esta pieza se puede clasificar como "botella" (recurriendo a la traducción de la nomenclatura portuguesa más común, i. e., "garrafa"; por ejemplo, Carvalho 2011) o como "cántaro" (si se adopta el término propuesto para los conjuntos de Valencia y Andalucía por Bernabeu 1989: 31), considerando la presencia de un cuello muy estrecho coronando una panza bastante ancha y su altura relativa.

Entre el cuello y la parte superior de la panza del vaso se emplaza el asa de cinta conservada, con un espesor semejante al de las paredes y más estrecha en su parte mesial. Posiblemente se tratase de un recipiente con dos o más asas, dispuestas verticalmente, resultando en una apertura horizontal. En la parte recuperada del vaso no se observan otros elementos plásticos, como por ejemplo pezones o cordones.

Si bien la decoración conservada en estos fragmentos se limita al cuello y a la parte superior de la panza del recipiente, no alcanzando los $10 \mathrm{~cm}$ por debajo del borde, se extiende profusamente por dicha superficie. Aunque la zona decorada es relativamente restringida, y no podemos por tanto descartar la existencia de bandas impresas en sectores más bajos del vaso, debemos reseñar que la zona decorada de este es precisamente la que en principio estaría más expuesta, y por lo tanto más visible, con la cerámica posada en el suelo. Este aspecto es determinante para entender el impacto pretendido mediante el dispositivo ornamental escogido por parte del artesano.

Un análisis macroscópico de los fragmentos permite concluir que estamos ante una pasta de textura arenosa, a veces con una estructura de aspecto laminar. Las inclusiones no plásticas visibles a simple vista son sobre todo silicatos (lo que confirma el análisis de lámina delgada; véase más abajo), muy angulosos y con una densidad relativamente elevada. La coloración de la pasta sugiere una cocción predominantemente oxidante: las paredes internas del vaso tienen colores marrones muy oscuros, casi negros, mientras que el exterior se acerca al marrón-rojo; la sección presenta tonos marrones claros. Es importante señalar que la superficie exterior de la pieza, bien alisada, se muestra de un rojo vivo, que sugirió en un primer examen la aplicación de almagra. Sin embargo, la observación más cuidadosa de las fracturas no permite detectar la fina película que la almagra, en principio, produciría, por lo que, a expensas de ulteriores análisis, debemos excluir esa posibilidad.

Como comentábamos anteriormente, el análisis técnico de la decoración permite concluir que toda ella fue producida mediante impresión (Fig. 4). En concreto se ha recurrido a aplicar el borde de conchas de berberecho (Cerastoderma edule), o especie/s similar/ es, como matriz para la producción de las impresiones observadas. Es decir, estamos ante la característica "impresión cardial", cuya designación deriva de la antigua clasificación taxonómica del mencionado molusco, Cardium edule, hoy en desuso.

La zona decorada del vaso está organizada en siete bandas de impresiones dispuestas, de forma alternada, en sentido vertical y horizontal. A partir del borde, la primera serie consiste en una estrecha banda de impresiones cardiales ordenadas verticalmente; le sigue una amplia franja de impresiones horizontales, formando líneas, que conjuntamente ocupan el resto del cuello y la parte superior de la panza, hasta alcanzar aproximadamente la mitad de la altura de las asas; a continuación y hasta el final de la zona decorada, se distinguen otras cuatro bandas, mucho más estrechas, alternando las impresiones verticales y horizontales.

A juzgar por los dos ejemplares conservados, las asas ostentarían una banda de impresiones cardiales horizontales cubriendo la totalidad de su superficie exterior, encuadradas a su vez por sendas líneas ver- 

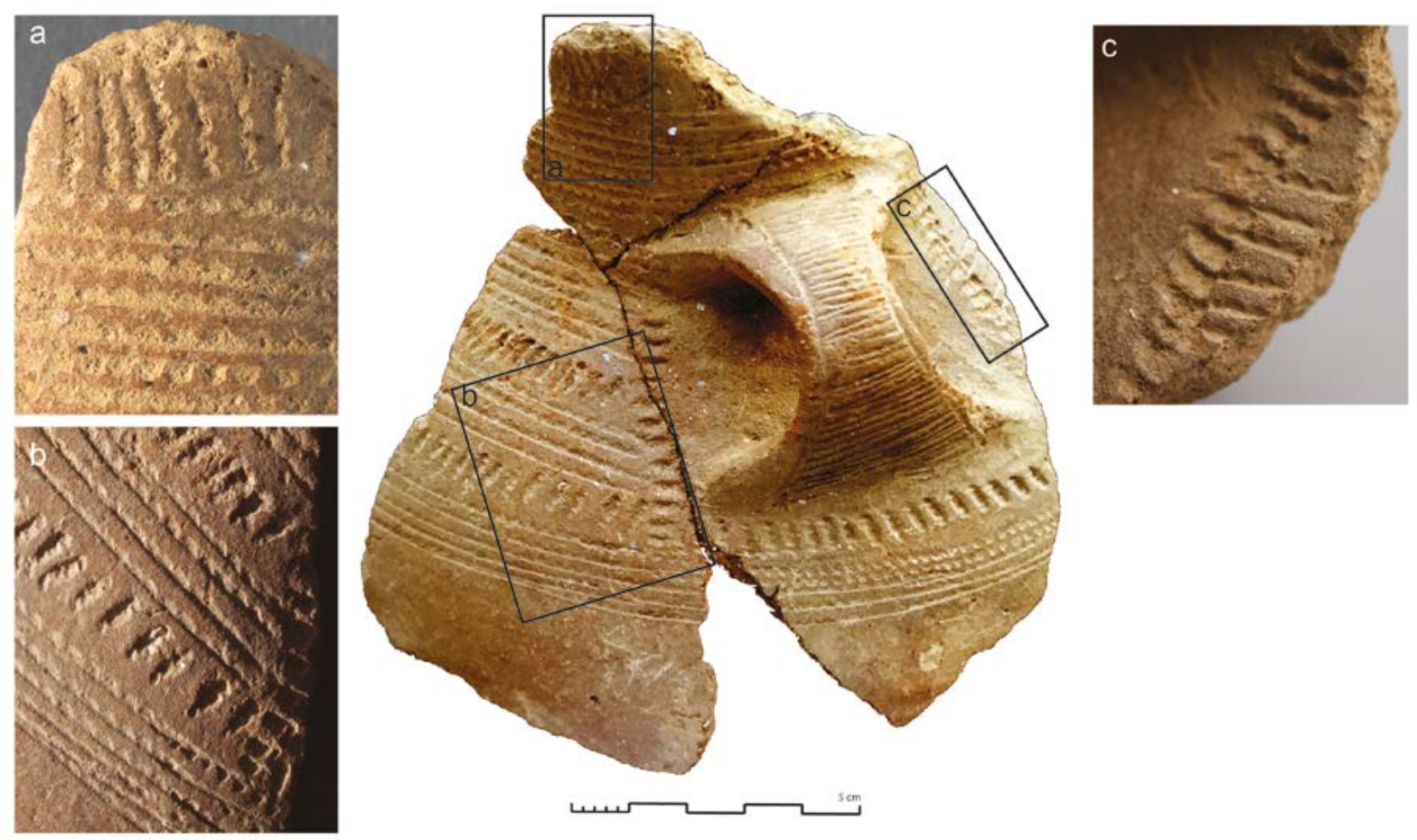

Fig. 4. Detalle de la decoración impresa en diferentes sectores de la cerámica cardial de Cova Eirós (en color en la edición electrónica).

ticales, aparentemente obtenidas mediante la yuxtaposición de impresiones cardiales que acaban formando un surco continuo y de traza algo irregular. El área bajo las asas, parcialmente oculta por las mismas, carece por completo de decoración.

\subsection{Análisis arqueométricos}

Los análisis mineralógico y de lámina delgada realizados en el Instituto de Cerámica de Galicia (F. Guitián Rivera) indican que el vaso fue elaborado a partir de arcillas propias de zonas graníticas y/o pizarrosas, con sedimentos poco procesados formados mayoritariamente por cuarzo y feldespato, mayormente de grano medio (50-150 micras) y grueso (150-500 micras). La cocción es oxidante (horno abierto, en fosa, etc) a temperaturas relativamente bajas $\left(<850^{\circ} \mathrm{C}\right)$. Los análisis de composición de las arcillas y los elementos traza identificados son compatibles con un origen autóctono de la cerámica, aunque no permiten hacer mayores precisiones al respecto.

Dada la singularidad del recipiente cerámico, consideramos necesario llevar a cabo el análisis de residuos orgánicos para establecer el uso y funcionalidad del mismo. Con este objetivo, se procedió a tomar una muestra de polvo cerámico ( $2 \mathrm{~g})$ de la superficie interior de un fragmento, previa limpieza con la finalidad de evitar las contaminaciones superficiales. El análisis de residuos orgánicos permite establecer la función de los recipientes alfareros a partir de los lípidos conservados en los poros de la matriz cerámica (Evershed 2008). La extracción de los lípidos fue realizada siguiendo los protocolos analíticos previamente establecidos mediante acidificación (Craig et al. 2013; Correa-Ascencio y Evershed 2014) y el uso de solventes orgánicos (Evershed 2008) para lo cual se utilizó $1 \mathrm{~g}$ de muestra respectivamente. Posteriormente, la muestra acidificada fue analizada directamente mediante cromatografía de gases con detector de ionización de llama (GC-FID), cromatografía de gases-espectrometría de masas (GC-MS) y cromatografía de gases-espectrometría de masas de relaciones isotópicas (GCc-IRMS), siguiendo los protocolos analíticos previamente publicados (Shoda et al. 2017). Por su parte, la muestra extraída mediante solvente fue analizada por cromatografía de gases-espectrometría de masas de alta temperatura (HTGC-MS).

La concentración de lípidos en la muestra $(29,23 \mu \mathrm{g}$ g-1) resultó superior a $5 \mu \mathrm{g}$ g-1, límite establecido como fiable para contener lípidos susceptibles de ser interpretados (Evershed 2008). Los lípidos extraídos 
de la muestra reflejan un amplio rango de componentes: la principal contribución procede de los ácidos grasos saturados (C12:0-C26:0, con predominio del $\mathrm{C} 16: 0)$ que aparecen junto a ácidos grasos monoinsaturados (C14:1; C16:1; C18:1; C22:1), ramificados (C15:0; C17:0) e isoprenoides (TMTD, pristánico y fitánico). También se ha identificado ftalato como principal contaminante relacionado con el almacenamiento en bolsas de plástico. En el análisis de la muestra extraída mediante solvente orgánico y analizada por cromatografía de masas de alta temperatura se identificó además la presencia de n-alcoholes y esteroles ( $\beta$-Sitosterol y derivados del colesterol). Entre los contaminantes, cabe destacar la identificación de escualeno.

El análisis mediante espectrometría de masas permitió identificar una muy buena concentración de ácido palmítico $(\mathrm{C} 16: 0=94,39 \mathrm{ng})$ frente a una baja preservación del ácido esteárico $(\mathrm{C} 18: 0=29,94 \mathrm{ng})$. Pese a ello se decidió llevar a cabo la cromatografía de gases-espectrometría de masas de relaciones isotópicas (GC-c-IRMS), que nos ha permitido obtener los valores $\delta 13 \mathrm{C}$ de los principales ácidos grasos hallados en la muestra: el ácido palmítico $(\mathrm{C} 16: 0)$ y el esteárico (C18:0). Los valores resultantes (813CC16:0: -26.9; 813CC18:0: -28.15; $\triangle 13 \mathrm{C}(\mathrm{C} 18: 0-\mathrm{C} 16: 0)$ : -1.25) reflejan una gran similitud con los valores isotópicos de referencia publicados en la bibliografía para tejido adiposo de rumiantes (Evershed et al. 1997, 2002; Copley et al. 2005); sin embargo, no se han identificado acilgliceroles (tri-, di- o monoacilglicéridos) en la espectrometría de masas de alta temperatura. La presencia de ácido palmítico y esteárico en los residuos de la cerámica ha sido también corroborada por un segundo análisis realizado en los servicios de la RIAIDT de la USC ${ }^{1}$. La existencia de esteroles ( $\beta$-Sitosterol) y la elevada abundancia de C16:0 podrían estar reflejando el procesado de recursos vegetales. En función de los resultados obtenidos, el recipiente cerámico indica un procesado de recursos cárnicos de rumiantes y vegetales.

\subsection{Comparaciones y propuesta cronológica}

La morfología del vaso de Cova Eirós se ajusta a lo que se ha venido denominando habitualmente como "botella" o "cántaro" y posee diversos paralelos formales en contextos del Neolítico Antiguo del sur y del este de la península ibérica (para trabajos recientes,

\footnotetext{
Análisis mediante GC/MS realizados por Esteban Amado Rodríguez (GEPN-AAT), Beatriz Rodríguez Garrido (IIAG-CSIC) y Esteban Guitián Fernández (RIAIDT-USC). Actualmente, en proceso de estudio e interpretación.
}

véanse p. ej. García et al. 2010, 2011; Bernabeu et al. 2011; Flors y Sanfeliu 2011). La presencia de decoración cardial refuerza, en definitiva, esa atribución genérica que, a falta de un contexto bien definido en términos estratigráficos en la propia cueva, debe ser considerada como firme y sugerente de una cronología antigua dentro del período neolítico. Por otra parte, las propias circunstancias del hallazgo, de carácter aislado, apuntan a que este vaso ha sido deliberadamente enterrado en aquel lugar, a semejanza de ejemplos similares en el occidente peninsular, hasta ahora circunscritos al centro-sur portugués y en su mayoría asignados, con base en comparaciones tipológicas, al VI milenio AC. Si bien alguna de esas formas en el Mediterráneo se prolonga hasta momentos algo más recientes, ya del V milenio (Flors y Sanfeliu 2011; Rosser y Soler 2016), su aparición en la fachada atlántica está estrechamente ligada al Neolítico Antiguo. Aunque tales descubrimientos no han merecido reflexión y discusión en grado suficiente, su recurrencia plantea la posibilidad de que estos vasos estén relacionados con algún tipo de manifestación ritual relacionada con el agua, pues en algunos casos hay, o parece haber, una relación directa con cursos de agua en las inmediaciones. Esta coincidencia fue primeramente observada por Simões (1999: 87), que menciona la rareza de paralelos peninsulares para los hallazgos similares lusos, añadiendo que "el depósito de recipientes cerámicos singulares, frecuentemente enteros, en áreas pantanosas o inundables constituye una de las características esenciales de las fases más antiguas del Neolítico en la actual Dinamarca [de donde se] deduce la suposición de hallarnos ante depósitos votivos de alimentos, en áreas limítrofes a los núcleos de población (Tilley 1996: 100)" (original en portugués). Dicho patrón de ubicación cercana a corrientes de agua se repite en otros hallazgos del territorio portugués (Carvalho 2011). De forma interesante, este parece ser también el caso del vaso estudiado aquí: la entrada de Cova Eirós se abre a unos $25 \mathrm{~m}$, en la vertical, sobre un pequeño curso de agua (regato de Bezcas) tributario del río Oribio, cuyo cauce desaparece a continuación en el seno del sistema cárstico para luego aflorar a unos $300 \mathrm{~m}$ al oeste, evocando de esa forma dinámicas observadas en los casos portugueses. Este hecho habrá de tenerse en cuenta a la hora de interpretar nuestro hallazgo, aunque no debemos olvidar que estamos moviéndonos en un terreno hipotético. Otra posibilidad reside en su vinculación con un uso funerario, siguiendo otros paralelos peninsulares conocidos. Si bien el contexto de la UA 8 no permite realizar inferencias concluyentes, la presencia de restos humanos en el interior de la cavidad apunta a su utilización como lugar de enterramiento cuando menos en los momentos finales del Neolítico (Fábregas et al. 2012b). 
En una síntesis que aún se puede considerar actualizada en sus aspectos principales, se recoge un total de cinco lugares en Portugal donde surgieron piezas equiparables al vaso de Cova Eirós, tanto en términos morfológicos como estilísticos, incluso por lo que se refiere a las circunstancias contextuales en que se encontraron (Carvalho 2011: 245-246, Fig. 11-5) (Fig. 1):

Casével (Condeixa-a-Nova): según la principal publicación que se refiere a él (Pessoa 1983), se trata de un vaso con cuello hallado en un terreno labrado, que presenta fondo cónico y tres asas de cinta decoradas, anchas y gruesas, con perforación horizontal, unidas por un cordón segmentado que incluye otras tantas asas del mismo tipo pero de perforación vertical. La decoración, compuesta, se organiza en dos bandas formadas por punzonado e incisión (una en el cuello, otra en la panza), bajo las cuales se suceden triángulos rellenos mediante punzonado arrastrado (Fig. 1B).

Santarém: de procedencia incierta, pero aparentemente de los alrededores de la capital de Ribatejo, este vaso presenta cuerpo panzudo, un cuello cilíndrico muy destacado y dos asas (Guilaine y Ferreira 1970). La decoración, exclusivamente cardial, se organiza en tres bandas paralelas al borde, cada una formada por series de impresiones con distintas orientaciones (Fig. 1C).

Cartaxo: las semejanzas entre esta pieza y la anterior, tanto en lo que se refiere a las condiciones de hallazgo como a su morfología general, fueron ya señaladas por Guilaine y Ferreira (1970). La principal diferencia entre ambas reside en la decoración, que aquí consiste en la aplicación de un cordón liso que une las partes superiores de tres asas de cinta, y en trazos incisos reticulados sobre las referidas asas.

Monte da Vinha (Santiago do Cacém): este vaso, prácticamente inédito (GAMNA 2005), proviene también de un hallazgo aislado. Presenta una forma ovoide con cuello alto, bajo el cual se disponen tres asas verticales. La decoración, impresa, se organiza en dos bandas: una inmediatamente junto al borde, otra, en guirnalda, uniendo los referidos elementos de prensión.

Retorta (Loulé): este yacimiento se corresponde con una necrópolis tardorromana donde Gomes et al. (2003: 16-17) recogieron un vaso que, si bien no ilustrado, se describe como de forma ovoide, cuello estrangulado y borde alto, provisto de cuatro pequeñas asas con perforación transversal, decorado mediante cordones en relieve, una tipología que permitió a los autores su atribución al Neolítico antiguo. No se conocen con precisión las condiciones en que se encontraba el vaso, pero no hay referencia a ningún contexto arqueológico neolítico en el lugar de donde pudiera ser originario.

Galeria da Cisterna do Sistema Cárstico da Gruta do Almonda (Torres Novas): se trata de la única apa- rición de vasos cardiales en forma de "botella" o "cántaro", con cuerpo que se presume ovoide (su reconstrucción completa no ha sido posible), en claro contexto arqueológico (aunque se trata de un palimpsesto). Según los trabajos publicados sobre las excavaciones realizadas en la década de 1980 en el pasillo de esta cavidad, fue posible definir dos fases en su ocupación cardial, denominadas "Cardial Antiguo" y "Cardial Reciente" (Zilhão 2009), la primera representada en términos cerámicos por dos vasos (designados como Vasos I y II), descritos así (Zilhão y Carvalho 2011: 252): "de cuello desarrollado, con asas anchas de perforación horizontal, y decoración extendida por toda la panza. La inexistencia de fragmentos correspondientes a fondos cónicos [como en el caso de Cova Eirós] indica que el cuerpo de estas piezas sería en 'saco', a semejanza, por ejemplo, del vaso de Santarém. El vaso I está decorado con impresiones a peine rellenas con pasta blanca y el vaso II con impresiones cardiales" (original en portugués). A estos vasos deberán asociarse las fechas de radiocarbono más antiguas disponibles para la Galeria da Cisterna, que se encuadran hacia 5500-5300 cal BC (sobre la cronología relativa y absoluta disponible para el Neolítico antiguo de esta cueva, véanse Zilhão 2009 y Carvalho 2018). Desafortunadamente, la referida seriación tipológica se infiere por paralelos generales con la secuencia levantina (Bernabeu 1989). La reconstrucción de la asociación espacial/altimétrica entre los fragmentos de los vasos cardiales de las dos fases y las muestras fechadas por radiocarbono -la única posibilidad de confirmar el modelo cronoestilístico propuesto- está pendiente.

Abrigo 2 de A Cunchosa (Cangas, Pontevedra): este es el único yacimiento, sito en un punto de la costa SO galaica, donde se registra una morfología en botella o cántaro dentro del territorio gallego. Aquí se recuperó un pequeño vaso con esas características y un segundo, de mayor tamaño, que también podría encajar en dicha categoría formal. Ambos poseen un tratamiento superficial cuidado y decoraciones impresas (punzón o ungulaciones) y sólo hay que lamentar su procedencia de hallazgos casuales (Suárez 1997; Fábregas y Suárez 1999).

En suma, considerando los paralelos formales y estilísticos que el vaso de Cova Eirós permite establecer con las realidades geográficamente más cercanas - es decir, el Abrigo 2 de A Cunchosa además de los sitios comentados del territorio centro-sur portuguésy la datación radiocarbónica obtenida en la Galeria da Cisterna, el único sitio del occidente peninsular donde estas formas cerámicas con decoración cardial fueron documentadas en contexto arqueológico, en el estado actual de la investigación podemos concluir que aquella será también la cronología aproximada del vaso de 


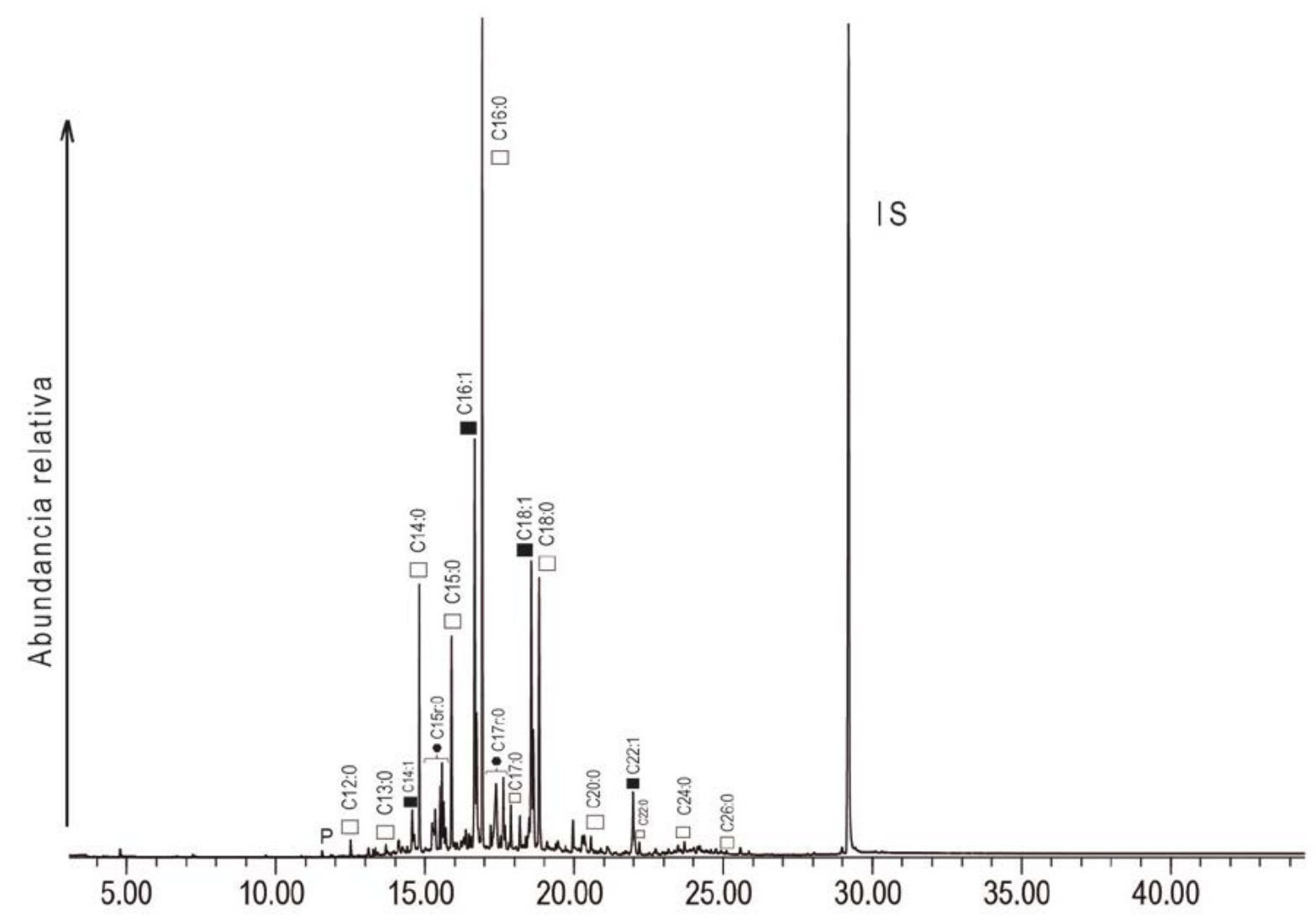

Fig. 5. Cromatograma de masas obtenido de la fracción acidificada de Cova Eirós. Abreviaturas: $\mathrm{C}_{\mathrm{n}: 0}$ ácidos grasos saturados con $\mathrm{N}$ átomos de carbono; $\mathrm{C}_{\mathrm{n}: 1}$ ácidos grasos insaturados con la indicación del número de enlaces dobles; $\mathrm{C}_{\mathrm{n}: 0}$ ácido graso ramificado; IS estándar interno $\left(\mathrm{C}_{36: 0}\right)$; P Ftalato.

Cova Eirós. Si este encuadre temporal se confirmase estaríamos ante la más antigua manifestación neolítica en territorio gallego.

\section{DISCUSIÓN: EL CARDIAL EN EL OCCIDENTE PENINSULAR Y EL PROCESO DE NEOLITIZACIÓN}

Hasta el descubrimiento del vaso de Cova Eirós, el bajo Mondego parecía señalar el límite septentrional de la distribución del Cardial, a tenor de los trabajos desarrollados en los sitios al aire libre de Várzea do Lírio, Junqueira y Forno da Cal (Rocha 1900), así como las excavaciones en la gruta de Eira Pedrinha (Corrêa y Teixeira 1949), todo ello recogido en la síntesis fundacional de Guilaine y Ferreira (1970) (Fig. 1A). La ocupación cardial de Senhora da Alegría (Coimbra), recientemente dada a conocer y que contendría fosos aparentemente datados de ese período
(Valera 2013), carece todavía de una publicación detallada y el vaso de bordes dentados con impresiones de concha del Sector VII en el yacimiento de Prazo (Vila Nova de Foz Côa), por tanto ya en el valle del Duero, no encaja en esta revisión al haber sido decorado mediante la aplicación de concha de Acanthocardia tuberculata (= Cardium tuberculatum) y, sobre todo, porque proviene de un nivel datado por radiocarbono hacia mediados del V milenio AC (MonteiroRodrigues 2011: 230 y Fig. 9.14). En otro orden de cosas, como ya hemos señalado en otro lugar (Carvalho 2018), se puede afirmar con toda propiedad que la realidad geográfica de la dispersión de los grupos cardiales parece haberse ceñido a los territorios de claro dominio de las condiciones bioclimáticas mediterráneas, cuyo límite septentrional en la fachada occidental de la península ibérica se sitúa precisamente en el Bajo Mondego.

Ante el panorama expuesto, es fácil concluir que el vaso de Cova Eirós resulta, en el estado actual de 
la investigación, una producción única, no sólo en el marco del noroeste peninsular como incluso en el territorio al norte del Mondego y plantea la cuestión de los mecanismos de llegada (si se tratase de una importación) o de trasmisión de técnicas y diseños (asumiendo la hipótesis de ser el fruto de la aculturación de poblaciones mesolíticas locales) que expliquen su presencia en esta zona interior de Galicia y, en claro contraste con el centro-sur portugués, plenamente atlántica en sus coordenadas ecológico-geográficas.

El hallazgo de un contexto con elementos cerámicos cardiales en La Paleta, cerca de Toledo, en pleno hinterland peninsular, sirvió para plantear la hipótesis de un proceso de llegada de grupos cardiales oriundos del Bajo Tajo que habrían seguido el curso de este río como vía de acceso directo a las regiones centrales de la península ibérica ${ }^{2}$. A pesar de las justas reservas planteadas desde entonces por lo que atañe a la fiabilidad de la muestra ("una masa heterogénea de material orgánico" según Bernabeu y Martí 2014: 428; véase también Rojo et al. 2018) utilizada en la datación radiocarbónica que sostiene una cronología tan precoz (circa 5700$5500 \mathrm{cal} \mathrm{BC}$ ) para este sitio, la hipótesis respecto al proceso responsable del establecimiento de ese grupo humano en la región toledana goza sin embargo de algún apoyo indirecto. Para empezar, en las condiciones paleogeográficas del Tajo durante el Holoceno Medio, cuya ría Flandriense se prolongaba hasta cerca de la mitad de su curso portugués (e. g. Vis et al. 2008), favoreciendo así su navegabilidad. Pero, tal vez más importante en esta discusión, sea la reciente verificación de que vasos cardiales recorrieron distancias incluso superiores a $350 \mathrm{~km}$ en estas regiones: un proyecto de investigación sobre procedencia y circulación de vasos neolíticos identificó el transporte de piezas cardiales entre el Algarve occidental y el centro de Portugal durante la segunda mitad del VI milenio AC, verosímilmente por vía marítima - cabotaje - y aprovechando las referidas facilidades de navegación a lo largo del curso bajo del Tajo (Masucci y Carvalho 2016).

Es en el marco de este modelo de circulación de objetos a larga distancia durante el Neolítico antiguo del occidente peninsular que deberá ser tenida en cuenta la vía de comunicación proporcionada por el valle del Miño y la verosímil importancia del SO galaico en la entrada del Neolítico en esta región, sin que podamos descartar tampoco las posibilidades de tránsito a lo largo de la depresión Régua-Verín, que pondría en contacto el interior de Galicia con el área trasmontana, donde se conocen yacimientos del Neolítico antiguo regional datados de la primera mitad del $\mathrm{V}$

2 Jiménez, J. 2008: La neolitización en el interior de la Península Ibérica. Universidad Complutense de Madrid. Tesis Doctoral inédita. milenio AC, entre los cuales el nivel IV.1 de Buraco da Pala (Sanches 1997), fechado circa 4800-4700 cal $\mathrm{BC}$ (Tab. 2), es claramente el más representativo en la región de Trás-os-Montes.

En esa misma perspectiva de interacciones suprarregionales es preciso tener en cuenta otros elementos que pueden sugerir la existencia de conexiones extraibéricas, con materias primas como la variscita llegada desde el occidente peninsular hasta Bretaña, la aparición de hachas de jadeíta alpina en diversos puntos de España y Portugal o la mencionada presencia en Galicia de cerámicas relacionables con el complejo Castellic (Fábregas et al. 2012a, 2017).

Cabe preguntarse, por otra parte, acerca de las circunstancias socioculturales que presidieron la llegada a Galicia del vaso eirosino, pues sus paralelos cardiales en el sur peninsular nos remontan hasta el VI milenio cal AC, un momento en el que con los conocimientos actuales es francamente aventurado hablar de un Neolítico establecido en el territorio gallego. Dejando a un lado el argumento de "ausencia de evidencia no equivale a evidencia de ausencia", se abren dos posibilidades para una presencia temprana de un artefacto tan diagnóstico. Una de ellas se basa en la noción de que nos hallamos ante la llegada de un pequeño grupo productor al piedemonte oriental de Galicia, acaso oriundos de un hipotético enclave neolítico ya instalado en el Baixo Miño. Si bien esta propuesta no está actualmente sustentada por el registro arqueológico regional o de la propia Cova Eirós, no carece de paralelos en otras áreas peninsulares, como la región centro-litoral portuguesa, entre los ríos Mondego y Tajo (e. g. Zilhão 1993; para una síntesis reciente, véase Carvalho 2018). Una interpretación alternativa sería que la obtención y uso de un artefacto marcadamente exótico puede vincularse a estrategias de emulación en el marco de sociedades cazadoras-recolectoras en una fase terminal de su existencia y que inician (o mantienen), mediante diversos mecanismos, contactos con grupos productores. El recurso a la manipulación de objetos de procedencia foránea y ajenos a las prácticas subsistenciales de las poblaciones mesolíticas podría ser una de las respuestas sociales a la existencia de alteraciones en el equilibrio ecológico y presumibles conflictos intergrupales. En efecto, algunos siglos antes del periodo que nos ocupa, los estudios paleobotánicos apuntan a que una brusca caída en el polen arbóreo, detectada en turberas del norte gallego hacia el 6410-5837 cal AC, podría deberse a la incidencia de factores climáticos pero también a una correlativa presión humana sobre el medio, recurriendo a los incendios de la masa forestal (Muñoz et al. 2005). Más al sur, el análisis de los carbones preservados en cinco depósitos coluviales de Campolameiro (Pontevedra) abunda en la tesis de los incendios forestales producidos por grupos mesolíticos hacia fines

Trab. Prehist., 76, N. ${ }^{\circ}$ 1, enero-junio 2019, pp. 147-160, ISSN: 0082-5638

https://doi.org/10.3989/tp.2019.12231 


\begin{tabular}{|c|c|c|c|c|c|c|c|c|c|c|c|c|c|c|c|c|}
\hline 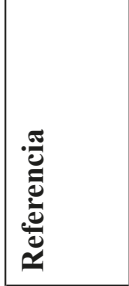 & 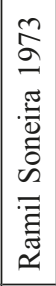 & 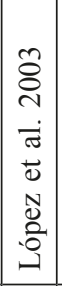 & 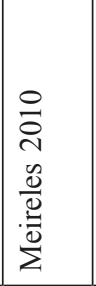 & 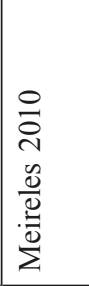 & 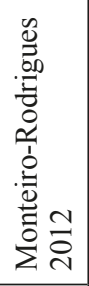 & 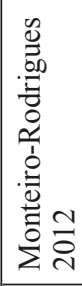 & 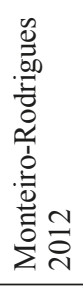 & 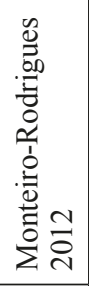 & 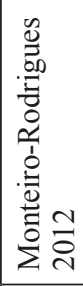 & 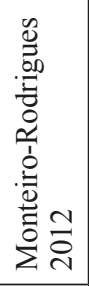 & 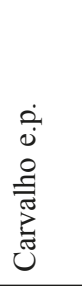 & 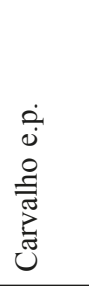 & 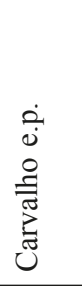 & 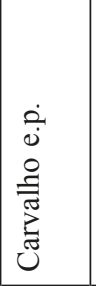 & 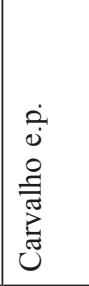 & 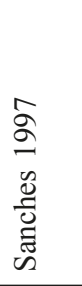 \\
\hline 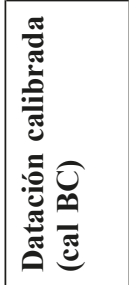 & $\begin{array}{l}0 \\
\infty \\
0 \\
\infty \\
n \\
n \\
1 \\
n \\
0 \\
n\end{array}$ & $\mid \begin{array}{c}0 \\
\infty \\
\infty \\
\infty \\
\infty \\
+ \\
\dot{1} \\
\infty \\
0 \\
i \\
\end{array}$ & 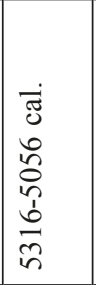 & 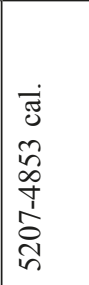 & 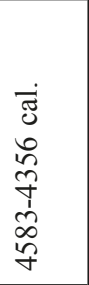 & 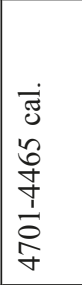 & 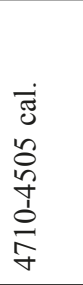 & 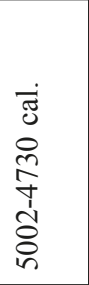 & 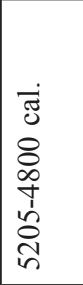 & 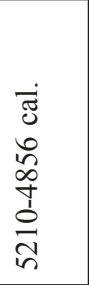 & 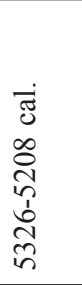 & 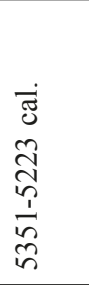 & 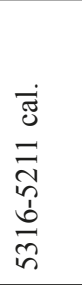 & 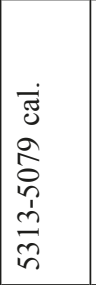 & 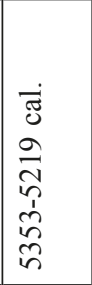 & 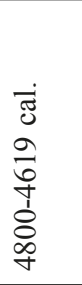 \\
\hline 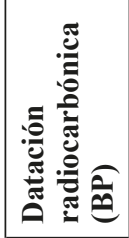 & $\begin{array}{l}2 \\
+1 \\
2 \\
8 \\
6\end{array}$ & 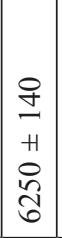 & 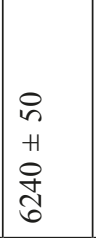 & $\begin{array}{l}\text { o } \\
+1 \\
8 \\
8 \\
8\end{array}$ & $\begin{array}{l}8 \\
i n \\
+1 \\
0 \\
\text { d } \\
n\end{array}$ & $\begin{array}{l}0 \\
i \\
H \\
n \\
\infty \\
i n \\
\end{array}$ & $\begin{array}{l}\text { P } \\
+1 \\
8 \\
8 \\
i n\end{array}$ & $\begin{array}{l}8 \\
+1 \\
+ \\
\circ \\
\text { in }\end{array}$ & $\begin{array}{l}8 \\
\text { in } \\
1 \\
n \\
2 \\
0\end{array}$ & $\begin{array}{l}8 \\
+1 \\
8 \\
8 \\
6\end{array}$ & 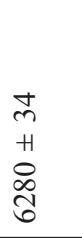 & $\begin{array}{l}\sqrt{2} \\
+1 \\
\sigma \\
\end{array}$ & 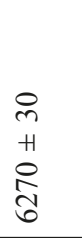 & $\begin{array}{l}0 \\
\text { r } \\
+1 \\
\tilde{n} \\
\tilde{\sigma}\end{array}$ & $\begin{array}{l}\vec{m} \\
+1 \\
\cdots \\
\cdots \\
\sigma\end{array}$ & $\begin{array}{l}\stackrel{p}{n} \\
+1 \\
\infty \\
D \\
\infty \\
i\end{array}$ \\
\hline 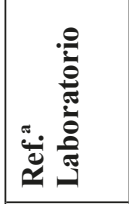 & $\begin{array}{l}\infty \\
0 \\
0 \\
0 \\
\tilde{n} \\
0\end{array}$ & 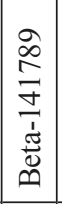 & 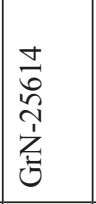 & 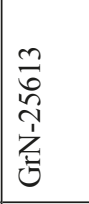 & 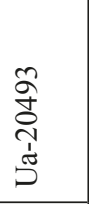 & 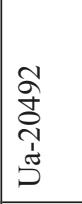 & $\begin{array}{l}\vec{m} \\
\frac{0}{\dot{\sigma}} \\
\frac{1}{3}\end{array}$ & 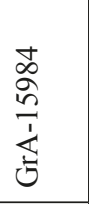 & 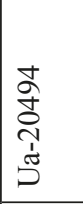 & 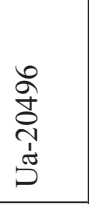 & $\begin{array}{l}n \\
\infty \\
\infty \\
\infty \\
N \\
\vdots \\
\vdots \\
0\end{array}$ & 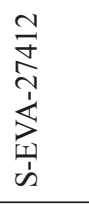 & $\begin{array}{l}+\frac{1}{n} \\
\hat{n} \\
\infty \\
\infty \\
\dot{n} \\
3\end{array}$ & $\begin{array}{l}n \\
n \\
\infty \\
\infty \\
1 \\
\dot{n} \\
3\end{array}$ & 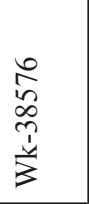 & $\frac{+}{0}$ \\
\hline 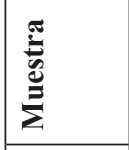 & 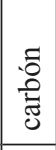 & $\Xi$ & 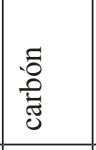 & 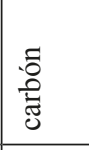 & 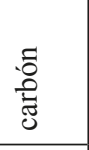 & 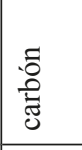 & 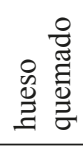 & $\begin{array}{l}0 \\
0 \\
0 \\
0 \\
\Xi \\
\end{array}$ & 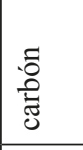 & 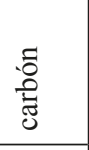 & 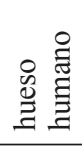 & 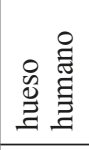 & 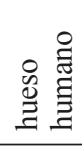 & 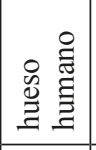 & 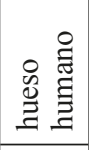 & 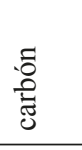 \\
\hline 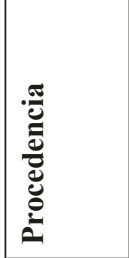 & 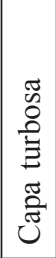 & $\left|\begin{array}{l}n \\
\vec{D} \\
\stackrel{z}{z}\end{array}\right|$ & 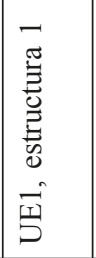 & 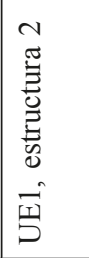 & 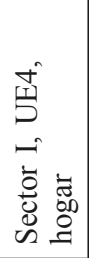 & 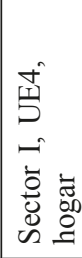 & 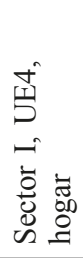 & 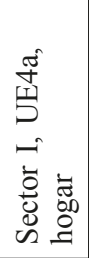 & 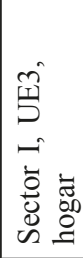 & 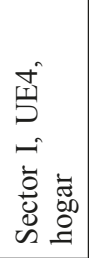 & 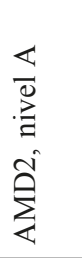 & 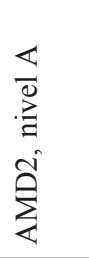 & 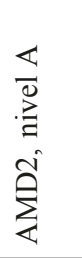 & 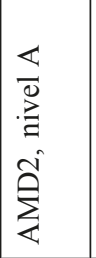 & 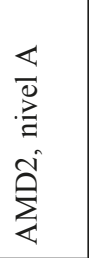 & $\begin{array}{l}\vec{z} \\
\vec{\Xi} \\
\vec{\exists}\end{array}$ \\
\hline 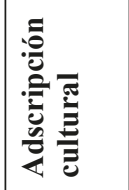 & $\begin{array}{l}\stackrel{0}{0} \\
: 0 \\
0 \\
0 \\
\stackrel{0}{0} \\
\Sigma\end{array}$ & 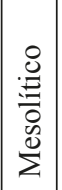 & 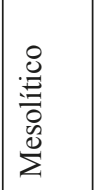 & 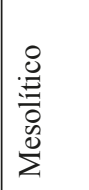 & 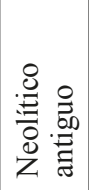 & 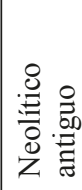 & 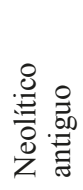 & 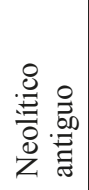 & 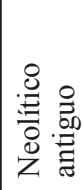 & 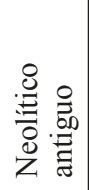 & 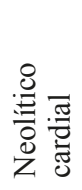 & 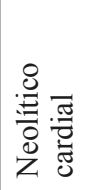 & 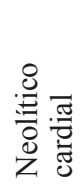 & 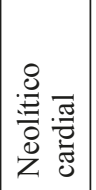 & 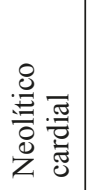 & 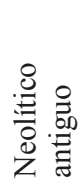 \\
\hline 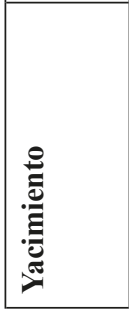 & 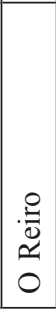 & \begin{tabular}{|l|}
0 \\
0 \\
$\tilde{z}$ \\
0 \\
2 \\
$z$ \\
\end{tabular} & 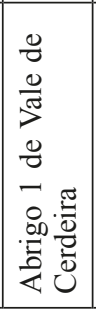 & 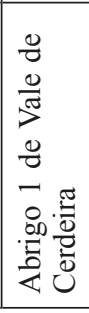 & \begin{tabular}{l}
$\stackrel{8}{\mathscr{J}}$ \\
\multirow{2}{*}{}
\end{tabular} & \begin{tabular}{l}
0 \\
\multirow{2}{*}{} \\
$\tilde{E}$
\end{tabular} & 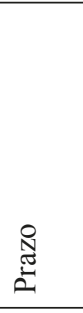 & 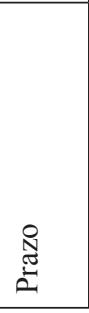 & 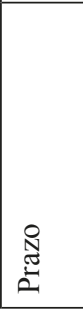 & \begin{tabular}{l}
0 \\
\multirow{Z}{*}{} \\
$\mathcal{E}$
\end{tabular} & 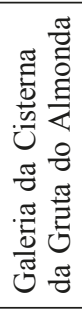 & 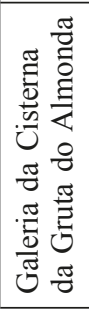 & 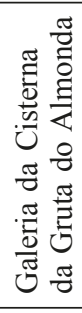 & 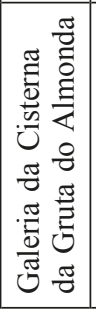 & 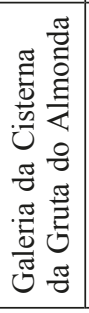 & 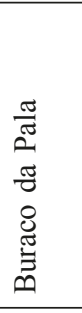 \\
\hline
\end{tabular}

Trab. Prehist., 76, N. ${ }^{\circ}$ 1, enero-junio 2019, pp. 147-160, ISSN: 0082-5638 https://doi.org/10.3989/tp.2019.12231 
del VI o comienzos del V milenio cal AC (Kaal et al. 2011). Al margen de los problemas de orden interpretativo que plantea la cuestión de los incendios intencionados durante el Mesolítico peninsular, la presencia de grupos cazadores-recolectores en coordenadas temporales inmediatamente pre-neolíticas está inequívocamente documentada en el Abrigo 1 de Vale Cerdeira (Vieira do Minho), no lejos de la presente frontera luso-gallega (Meireles 2010). Más al norte, la evidencia disponible es mucho más tenue y se ciñe a un depósito turboso en O Reiro (Arteixo, A Coruña) con restos de fauna e industrias líticas y una fecha radiocarbónica de mediados del VI milenio (5645-5383 cal BC, aunque debemos considerarla con precaución al desconocerse la procedencia exacta de la muestra; Ramil 1973), o las parcas evidencias materiales del nivel 5 de As Pontes (Abadín, Lugo) con una ocupación de carácter episódico, datada hacia el 5476-4814 cal BC (López et al. 2003). En resumen, con los escasos datos actuales de la investigación, se puede aventurar que el proceso de neolitización del noroeste peninsular parece seguir un modelo en mosaico análogo al documentado para la Cornisa Cantábrica (Fano et al. 2015).

\section{CONCLUSIONES}

La tipología específica del vaso encontrado en Cova Eirós (forma de botella, decoración con impresiones cardiales) y las condiciones particulares de su aparición (aparentemente aislado, sin contexto arqueológico definido), proporcionan elementos muy singulares para la discusión del proceso de neolitización de la región gallega y, por extensión, de todo el noroeste peninsular. Por un lado, los paralelos formales y estilísticos que hemos traído a colación permiten datar ese recipiente cerámico - provisionalmente- (la Galeria da Cisterna es el único referente obtenido en excavación que dispone de fechas radiocarbónicas), hacia finales del VI milenio AC, lo que nos sitúa en un segmento temporal para el que hasta el momento no se conocen contextos arqueológicos bien datados en toda la región, norte de Portugal incluido (para el caso del sitio fozcoense de Prazo, véanse Monteiro-Rodrigues 2011, 2012 vs. Zilhão 2003; Tab. 2). Por otra parte, el hecho de que se trata de un hallazgo aislado remite inmediatamente a circunstancias similares registradas en el territorio portugués y que se han interpretado en términos de deposiciones votivas, de carácter aún mal definido.

El significado último de la presencia de este vaso en Cova Eirós -en el sector oriental de Galicia y no en una zona costera, como cabría esperar- está muy lejos de ser unívoco. Las posibilidades interpretativas que hemos introducido más atrás: penetración de un grupo neolítico en "territorios de frontera", o bien adquisición de un "bien de prestigio" por grupos mesolíticos, no son en realidad totalmente excluyentes. Esta ambivalencia ilustra adecuadamente el carácter extraordinario que reviste ese descubrimiento, pero también el vasto territorio que queda por explorar desde la arqueología y que abarca no sólo los mecanismos y la cronología de la introducción de la economía productora (y la ergología asociada) sino, lo que es más importante, un mejor conocimiento de los grupos mesolíticos terminales en el noroeste, con toda probabilidad actores clave en la adopción de un modo de vida neolítico.

\section{BIBLIOGRAFÍA}

Bernabeu, J. 1989: La tradición cultural de las cerámicas impresas en la zona oriental de la Península Ibérica. Diputación Provincial de Valencia. Valencia.

Bernabeu, J.; Gómez, O.; Molina, L. y García, P. 2011: “La cerámica neolítica durante el VI milenio cal AC en el Mediterráneo central peninsular". En J. Bernabeu, M. A. Rojo y L. Molina (eds.): Las primeras producciones cerámicas: el VI milenio cal AC en la Península Ibérica. Saguntum Extra 12, Universitat de València. València: $153-178$

Bernabeu, J. y Martí, B. 2014: "The first agricultural groups in the Iberian Peninsula". En C. Manen, T. Perrin y J. Guilaine (eds.): $L a$ transition néolithique en Méditerranée. Errance / AEP Paris: 419-438.

Bronk Ramsey, C. 2009: "Bayesian analysis of radiocarbon dates". Radiocarbon 51 (1): 337-360.

Carvalho, A. F. 2011: "Produção cerâmica no início do Neolítico de Portugal”. En J. Bernabeu, M. A. Rojo y L. Molina (eds.): Las primeras producciones cerámicas: el VI milenio cal AC en la Península Ibérica. Saguntum Extra 12, Universitat de València. València: 237-250.

Carvalho, A. F. 2018: "When the Mediterranean met the Atlantic. A socio-economic view on Early Neolithic communities in centralsouthern Portugal". Quaternary International 470: 472-484. https:// doi.org/10.1016/j.quaint.2016.12.045

Cassen, S. ; Boujot, C. ; Domínguez Bella, S. ; Guiavarc'h, M. ; Le Pennec, C. ; Prieto Martínez, M. P.... y Vigier, E. 2012: ’Dépôts bretons, tumulus carnacéens et circulations à longue distance". En P. Pétrequin, S. Cassen, M. Errera, L. Klassen, A. Sheridan y A. M. Pétrequin (eds.): Jade. Grandes haches alpines du Néolithique européen. Ve et IVe millénaires av. J.-C. Cahiers de la MSHE C.N. Ledoux, Presses Universitaires de Franche-Comté et Centre de Recherche Archéologique de la Vallée de 1'Ain 2. Besançon: 918-995.

Copley, M. S.; Berstan, R.; Mukherjee, A. J.; Dudd, S. N.; Straker, V.; Payne, S. y Evershed, R. P. 2005: "Dairying in Antiquity. III. Evidence from absorbed lipid residues dating to the British Neolithic". Journal of Archaeological Science 32: 523-546. https://doi. org/10.1016/j.jas.2004.08.006

Corrêa, A. M. y Teixeira, C. 1949: A jazida pré-histórica de Eira Pedrinha (Condeixa). Serviços Geológicos de Portugal. Lisboa.

Correa-Ascencio, M. y Evershed, R. P. 2014: "High throughput screening of organic residues in archaeological potshers using direct acidief methanol extraction". Analytical Methods 6: 1330-1340. https://doi. org/10.1039/c3ay41678j

Craig, O. E.; Saul, H.; Lucquin, A.; Nishida, Y.; Taché, K.; Clarke, L.... y Jordan, P. 2013: "Earliest evidence for the use of pottery". Nature 496 (7445): 351-354. https://doi.org/10.1038/nature12109

Cubas, M.; Altuna, J.; Álvarez-Fernández, E.; Armendáriz, A.; Fano, M. A.; López-Dóriga, I.... y Arias, C. 2016: "Re-evaluating the Neolithic: the impact and consolidation of farming practices in the Can-

Trab. Prehist., 76, N. ${ }^{\circ}$ 1, enero-junio 2019, pp. 147-160, ISSN: 0082-5638

https://doi.org/10.3989/tp.2019.12231 
tabrian region (northern Spain)". Journal of World Prehistory 29 (1): 79-116. https://doi.org/10.1007/s10963-016-9091-2

Evershed, R. P. 2008: "Organic residue analysis in archaeology: the archaeological biomarker revolution". Archaeometry 50: 895-924. https://doi.org/10.1111/j.1475-4754.2008.00446.x

Evershed, R. P.; Dudd, S. N.; Copley, M. S. y Mukherjee, A. J. 2002: "Identification of animal fats via compound specific $\delta 13 \mathrm{C}$ values of individual fatty acids: assessment of results for reference fats and lipid extracts of archaeological pottery vessels". Documenta Praehistorica XXIX: 73-96. https://doi.org/10.4312/dp.29.7

Evershed, R. P.; Mottram, H. M.; Dudd, S. N.; Charters, S.; Stott, A. W.; Lawrence, G. J.... y Reeves, V. 1997: "New criteria for the identification of animal fats preserved in archaeological pottery". $\mathrm{Na}$ turwissenschaften 84: 402-406. https://doi.org/10.1007/ s001140050417

Fábregas Valcarce, R.; Bonilla Rodríguez, A. y Cesar Vila, M. 2007: Monte dos Remedios (Moaña, Pontevedra). Un asentamiento de la Prehistoria reciente. Tórculo Edicións. Santiago de Compostela.

Fábregas Valcarce, R.; Fernández Rodríguez, C. y Ramil Rego, P. 1997: "La adopción de la economía productora en el Noroeste ibérico". En A. Rodríguez Casal (ed.): O Neolitico atlántico e as orixes do megalitismo. Universidade de Santiago de Compostela. Santiago de Compostela: 463-484.

Fábregas Valcarce R.; Lombera Hermida A. de y Rodríguez Rellán, C. 2012a: "Spain and Portugal: long chisels and perforated axes. Their context and distribution“. En P. Pétrequin, S. Cassen, M. Errera, L. Klassen y A. Sheridan (eds.): Jade. Grandes haches alpines du Néolithique européen. Ve et IVe millénaires av. J.-C. Cahiers de la MSHE C.N. Ledoux, Presses Universitaires de Franche-Comté 2. Besançon: 1108-1135.

Fábregas Valcarce, R.; Lombera Hermida, A. de; Serna González, M. R.; Vaquero Rodríguez, M.; Pérez Rama, M.; Grandal D’Anglade, A.... y Ameijenda Iglesias, A. 2012b: “Ocupacións prehistóricas e históricas nas cavidades das Serras Orientais galegas. As covas de Eirós (Triacastela) e Valdavara (Becerreá)". Gallaecia 3: 19-46.

Fábregas Valcarce, R.; Rodríguez Rellán, C. y Lombera Hermida, A. de 2017: "Des Alpes à la Péninsule Ibérique: une longue route sinueuse". En P. Pétrequin, E. Gauthier y A.-M. Pétrequin (eds.): Objetssignes et interprétations sociales des jades alpins dans l'Europe néolithique. Cahiers de la MSHE C.N. Ledoux, Presses Universitaires de Franche-Comté 3. Besançon: 419-430.

Fábregas Valcarce, R. y Suárez Otero, J. 1999: "El proceso de neolitización en Galicia”. En J. Bernabeu Aubán y T. Orozco Köhler (eds.): Actes del II Congrés del Neolític a la Península Ibèrica (Valencia 1999). Saguntum. Papeles del Laboratorio de Arqueología de Valencia, Extra 2: 541-548.

Fano, M. Á.; Cubas, M. y Wood, R. 2015: "The first farmers in Cantabrian Spain: Contribution of numerical chronology to understand an historical process". Quaternary International 364: 153-161. https:// doi.org/10.1016/j.quaint.2014.09.026

Flors Ureña, E. y Sanfeliu, D. 2011: "La cerámica neolítica de Costamar (Cabanes, Castellón)". En J. Bernabeu, M. A. Rojo y L. Molina (eds.): Las primeras producciones cerámicas: el VI milenio cal AC en la Península Ibérica. Saguntum Extra 12, Universitat de València. València: 187-200.

GAMNA [Grupo de Amigos do Museu Nacional de Arqueologia] 2005: "O MNA recebe acervos notáveis: vaso do Monte da Vinha; espólio da Gruta do Correio-Mor". Boletim Informativo 5: 1.

García, P.; Aura, E.; Bernabeu, J. y Jordá, J. F. 2010: "Nuevas perspectivas sobre la neolitización la Cueva de Nerja (Málaga-España): la cerámica de la Sala del Vestíbulo". Zephyrus 66: 109-132.

García, P.; Aura, J. E. y Jordá, J. F. 2011. "La cerámica decorada del Neolítico antiguo de la Cueva de Nerja (Málaga, España). La Sala del Vestíbulo". En J. Bernabeu, M. A. Rojo y L. Molina (eds.): Las primeras producciones cerámicas: el VI milenio cal AC en la Península Ibérica. Saguntum Extra 12, Universitat de València. València: 217-230.

Gomes, M. V.; Paulo, L. C. y Ferreira, S. D. 2003: Levantamento arqueológico do Algarve. Concelho de Albufeira. Albufeira.
Guilaine, J. y Ferreira, O. V. 1970: "Le Néolithique ancien au Portugal". Bulletin de la Société Préhistorique Française 67 (1): 304322. https:// doi.org/10.3406/bspf.1970.4199

Kaal, J.; Carrión, Y.; Asouti, E.; Martín, M.; Martínez, A.; Costa, M. y Criado, F. 2011: "Long-term deforestation in NW Spain: linking the Holocene fire history to vegetation change and human activities". Quaternary Science Reviews 30: 161-175. https://doi.org/10.1016/j. quascirev.2010.10.006

Lombera Hermida, A. de; Rodríguez Álvarez, X. P. y Fábregas Valcarce, R. 2014: "El yacimiento arqueo-paleontológico de Cova Eirós (Triacastela, Lugo)”. En R. Sala, E. Carbonell, J. M. Bermúdez de Castro y J. L. Arsuaga (eds.): Los cazadores recolectores del Pleistoceno y del Holoceno en Iberia y el Estrecho de Gibraltar. Estado actual del conocimiento del registro arqueológico. Universidad de Burgos. Fundación Atapuerca. Burgos: 18-25.

López Sáez, J. A.; Parcero Oubiña, C.; Lima Oliveira, E.; López García, P.; Criado Boado, F.; Macías Rosado, R.... y Franco Maside, S. 2003 : "Paleopaisajes concretos: polen, suelos y arqueología del yacimiento de As Pontes (Abadín, Lugo)". Trabajos de Prehistoria 60 (1): 139-151. https://doi.org/10.3989/tp.2003.v60.i1.126

Masucci, M. A. y Carvalho, A. F. 2016: "Ceramic technology and resource use during the Neolithic in Central-Southern Portugal". Archaeometry 58 (2): 201-221. https://doi.org/10.1111/arcm.12206

Meireles, J. 2010: "Os últimos caçadores-recolectores da Serra da Cabreira (NO de Portugal). O Abrigo 1 de Vale de Cerdeira (Vieira do Minho)". En A. M. S. Bettencourt, M. I. C. Alves y S. MonteiroRodrigues (eds.): Variações paleoambientais e evolução antrópica no Quaternário do ocidente peninsular. APEQ / Centro de Investigação Transdisciplinar "Cultura, Espaço e Memória”. Braga: 83-96.

Monteiro-Rodrigues, S. 2011: Pensar o Neolítico antigo. Contributo para $o$ estudo do Norte de Portugal entre o VII e o V milénio a.C. Estudos Pré-Históricos 16, Centro de Estudos Pré-Históricos da Beira Alta. Viseu.

Monteiro-Rodrigues, S. 2012: "Novas datações pelo carbono 14 para as ocupações holocénicas do Prazo (Freixo de Numão, Vila Nova de Foz Côa, norte de Portugal)". Estudos do Quaternário 8: 22-37.

Muñoz Sobrino, C.; Ramil-Rego, P.; Gómez-Orellana, L. y Díaz Varela, R. A. 2005: "Palynological data on major Holocene climatic events in NW Iberia". Boreas 34 (3): 381-400. https://doi. org/10.1080/03009480510013006

Pessoa, M. 1983: "Vaso neolítico de Casével". Arqueologia 7: 16-23.

Querré, G.; Cassen, S. y Calligaro, T. 2015: "Témoin d'échanges au Néolithique le long de la façade atlantique: la parure en variscite des tombes de l'ouest de la France". En N. Naudinot, L. Meignen, D. Binder y G. Querré (eds.): Les systèmes de mobilité de la Préhistoire au Moyen Age. XXXVe Rencontres internationales d'archéologie et d'histoire d'Antibes, 14-16 oct. 2014. Editions APDCA. Antibes: 403-418.

Ramil Soneira, J. 1973: "Paradero de Reiro". Cuadernos de Estudios Gallegos XXVIII, 84: 23-31.

Reimer, P. J.; Bard, E.; Bayliss, A.; Beck, J.W.; Blackwell, P.G.; Bronk Ramsey, C. y van der Plicht, J. 2013: "IntCal13 and Marine13 Radiocarbon Age Calibration Curves 0-50,000 Years cal BP". Radiocarbon 55: 1869-1887. https://doi.org/10.2458/azu_js_rc.55.16947

Rey-Rodríguez, I.; López-García, J. M.; Bennasar, M.; Bañuls-Cardona, S.; Blain, H-A.; Blanco-Lapaz, A.... y Fábregas Valcarce, R. 2016: "Last Neanderthals and first Anatomically Modern Humans in the NW Iberian Peninsula: Climatic and environmental conditions inferred from the Cova Eirós small-vertebrate assemblage during MIS 3". Quaternary Science Reviews 151: 185-197. https://doi. org/10.1016/j.quascirev.2016.08.030

Rocha, A. S. 1900: Antiguidades prehistoricas do concelho da Figueira: memoria offerecida ao Instituto de Coimbra, Quarta Parte. Imprensa da Universidade. Coimbra.

Rodríguez Álvarez, X. P.; Lombera Hermida, A. de; Fábregas Valcarce, R. y Lazuén Fernández, T. 2011: "The Upper Pleistocene site of Cova Eirós (Triacastela, Lugo, Spain)". En A. de Lombera Hermida y R. Fábregas Valcarce (eds.): To the West of Spanish Cantabria: the Palaeolithic Settlement of Galicia. British Archaeological Reports International series 2283, Archaeopress. Oxford: 123-133. 
Rodríguez Casal, A. 1989: La necrópolis megalítica de Parxubeira. Monografías Urxentes do Museu, 4, A Coruña.

Rodríguez Casal, A. 1990: O megalitismo. A primeira arquitectura monumental de Galicia. Biblioteca de Divulgación, Serie Galicia 4, Universidade de Santiago de Compostela. Santiago de Compostela.

Rojo, M. Á.; García, I. y Royo, J. I. 2018: "The beginning of the Neolithic in the mid-Ebro valley and in Iberia's inland (northern and southern Submeseta), Spain”. Quaternary International 470: 398438. https://doi.org/10.1016/j.quaint.2017.12.037

Rosser, P. y Soler, S. 2016: "Propuesta de fases cronológicas para el asentamiento neolítico del Tossal de les Bases (Alicante, España)". Del neolític a l'edat del bronze en el Mediterrani occidental. Estudis en homenatge a Bernat Marti Oliver. Serie de Trabajos Varios 119, SIP, Diputación de Valencia. Valencia: 225- 248.

Sanches, M. J. 1997: O Abrigo do Buraco da Pala (Mirandela) no contexto da Pré-História recente de Trás-os-Montes e Alto Douro. Sociedade Portuguesa de Antropologia e Etnologia. Porto.

Shoda, S.; Lucquin, A.; Ahn, J.-H.; Hwang, C.-J. y Craig, O. E. 2017: "Pottery use by early Holocene hunter-gatherers of the Korean peninsula closely linked with the exploitation of marine resources". Quaternary Science Reviews 170: 164-173. https://doi.org/10.1016/j. quascirev.2017.06.032

Simões, T. 1999: O sitio neolítico de S. Pedro de Canaferrim, Sintra. Contribuições para o estudo da neolitização da Península de Lisboa. Instituto Português de Arqueologia. Lisboa.

Suárez Otero, J. 1983: "Os abrigos da Cunchosa. Novos datos sobre tipos de asentamentos e complexos ergolóxicos na prehistoria galega". Cuadernos de Estudios Gallegos XXXIV, 99: 51-86.

Suárez Otero, J. 1997: "Del yacimiento de A Cunchosa al neolítico en Galicia. Primera aproximación al contexto cultural de la aparición del megalitismo en Galicia”. En A. Rodríguez Casal (ed.): O Neolítico atlántico e as orixes do megalitismo. Universidade de Santiago de Compostela. Santiago de Compostela: 485- 506.

Teira Brión, A.; Martín Seijo, M.; de Lombera Hermida, A.; Fábregas Valcarce, R. y Rodríguez Álvarez, X. P. 2012: "Forest resources management during Roman and Medieval cave occupations in the Northwest of the Iberian Peninsula: Cova do Xato and Cova Eirós (Galicia, Spain)”. En E. Badal, Y. Carrión, M. Macías y N. Ntinou (eds.): Wood and charcoal. Evidence for human and natural history. Sagvntvm Extra 13: 159-166.

Tilley, C. 1996: An ethnography of the Neolithic. Early prehistoric societies in southern Scandinavia. Cambridge University Press. Cambridge.

Valera, A. C. 2013: "Cronologia dos recintos de fossos da Pré-História recente em território português". En J. M. Arnaud, C. Neves y A. Martins (eds.): Arqueologia em Portugal: 150 anos. Associação dos Arqueólogos Portugueses. Lisboa: 335-343.

Vázquez Varela, J. M. 1980: Las raíces de Galicia. Sálvora. Santiago de Compostela.

Vidal Romaní, J. R.; Sanjurjo Sánchez, J.; Grandal D’Anglade, A.; Vaqueiro Rodríguez, M. y Fernández Mosquera, D. 2010: “Geocaracterización de yacimientos arqueológicos en medio sedimentario: cronología absoluta y relativa”. En A. J. López Díaz y E. Ramil Rego (eds.): Arqueoloxía: Ciencia e Restauración. Monografías 4, Museo de Prehistoria e Arqueoloxía de Vilalba. Vilalba: 7-19.

Vis, G.-J.; Kasse, C. y Vanderberghe, J. 2008: "Late Pleistocene and Holocene palaeogeography of the Lower Tagus Valley (Portugal): effects of relative sea level, valley morphology and sediment supply". Quaternary Science Reviews 27: 1682-1709. https://doi.org/10.1016/j. quascirev.2008.07.003

Zilhão, J. 1993: "The spread of agro-pastoral economies across Mediterranean Europe: a view from the Far West". Journal of Mediterranean Archaeology 6 (1): 5-63. https://doi.org/10.1558/jmea.v6i1.5

Zilhão, J. 2003: "Algumas observações acerca do Mesolítico do interior peninsular e do modelo de passagem ao Neolítico através de colonização pioneira por via marítima". Comentário a: Carvalho, A. F.: A emergência do Neolítico no actual território português: pressupostos teóricos, modelos interpretativos e a evidência empírica. $O A r$ queólogo Português Série IV, 21: 108-118.

Zilhão, J. 2009: "The Early Neolithic artifact assemblage from the Galeria da Cisterna (Almonda karstic system, Torres Novas, Portugal)". En De Méditerranée et d'ailleurs... Hommages à Jean Guilaine. Archives d'Écologie Préhistorique. Toulouse: 821-835.

Zilhão, J. y Carvalho, A. F. 2011: "Galeria da Cisterna (Rede Cárstica da Nascente do Almonda)". En J. Bernabeu, M. A. Rojo y L. Molina (eds.): Las primeras producciones cerámicas: el VI milenio cal $A C$ en la Península Ibérica. Saguntum Extra 12: 251-254. 